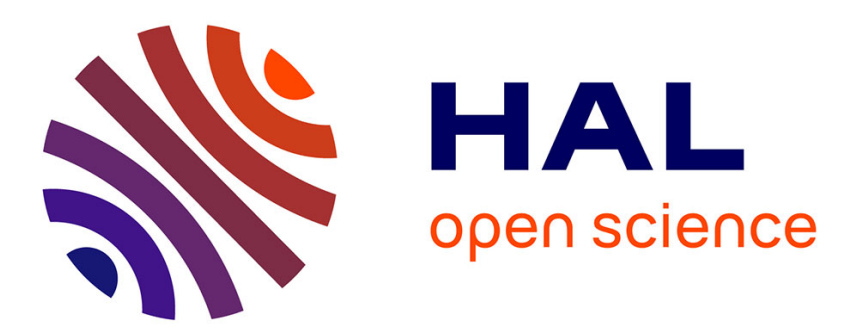

\title{
Fabric evolution during hydromechanical loading of a compacted silt
}

Olivier Cuisinier, Lyesse Laloui

\section{To cite this version:}

Olivier Cuisinier, Lyesse Laloui. Fabric evolution during hydromechanical loading of a compacted silt. International Journal for Numerical and Analytical Methods in Geomechanics, 2004, 28 (6), pp.483-499. 10.1002/nag.348 . hal-01754070

\section{HAL Id: hal-01754070 \\ https://hal.univ-lorraine.fr/hal-01754070}

Submitted on 30 Mar 2018

HAL is a multi-disciplinary open access archive for the deposit and dissemination of scientific research documents, whether they are published or not. The documents may come from teaching and research institutions in France or abroad, or from public or private research centers.
L'archive ouverte pluridisciplinaire HAL, est destinée au dépôt et à la diffusion de documents scientifiques de niveau recherche, publiés ou non, émanant des établissements d'enseignement et de recherche français ou étrangers, des laboratoires publics ou privés. 


\title{
FABRIC EVOLUTION DURING HYDROMECHANICAL LOADING OF A COMPACTED SILT
}

\author{
Olivier CUISINIER ${ }^{1}$ and Lyesse LALOUI ${ }^{2 *}$
}

1: Researcher

Soil Mechanics Laboratory

Swiss Federal Institute of Technology Lausanne (EPFL)

1015 Lausanne, Switzerland

2: Senior Researcher

Soil Mechanics Laboratory

Swiss Federal Institute of Technology Lausanne (EPFL)

1015 Lausanne, Switzerland

* Corresponding author:

e-mail : Lyesse.Laloui@epfl.ch

Phone: +41 216932314

Fax: +41216934153 


\title{
FABRIC EVOLUTION DURING HYDROMECHANICAL LOADING OF A COMPACTED SILT
}

\section{Olivier CUISINIER and Lyesse LALOUI}

\begin{abstract}
A study was undertaken on a compacted silt to determine fabric modifications induced by suction and/or stress variations. The link between fabric and hydromechanical behaviour was also investigated. A suction-controlled oedometer, using air overpressure, was developed for this purpose and mercury intrusion porosimetry was employed to determine sample fabric. The initial samples fabric was made of macro and micropores. It was shown that suction increase produced a strong decrease in the macroporosity associated with an increase in microporosity. However, some macropores were not significantly affected by the suction increase; this phenomenon might be related to the initial fabric of the samples. Second, it appears that loading under saturated conditions also produces strong fabric modification: the higher the applied stress, the lower the macroporosity. Soil fabric depends on the maximum stress experienced by the soil. Finally, some tests have shown the influence of suction, as well as the role of the degree of saturation, on the deformation process and the mechanical behaviour. The test results show that in the case of unsaturated mechanical loading, all macropores are not destroyed by the mechanical loading.
\end{abstract}

\section{Keywords:}

Compacted Soil; Fabric; Suction; Pore-Size Distribution; Hydromechanical Behaviour. 


\section{INTRODUCTION}

Soil fabric is of great importance in geotechnical, geoenvironmental and agricultural engineering as this property influences many soil characteristics, such as compressibility [1], hydraulic conductivity [2] or the soil-water characteristic curve [3] of both compacted and natural soils. Consequently, improving the understanding of fabric modifications induced by hydromechanical loads is a key issue and the aim of the study presented in this paper is to give insight into that relationship.

Soil fabric corresponds to the geometrical arrangement of soil particles [4]. When dealing with compacted soils, it is well known that on the wet side of the optimum, compacted soils have a homogenous fabric, whereas on the dry side they exhibit a fabric with macro and micropores $[5,6,7]$. Such soil fabric was termed "double structure" [8]. In the case of such soils, a few studies have been undertaken to characterise fabric changes induced by various types of hydromechanical loads. One point of interest involved fabric modifications provoked by saturated mechanical loading. Delage and Lefebvre (1984) [9], studying compacted Champlain clay fabric with mercury intrusion porosimetry and scanning electron microscopy, have shown that, during consolidation, only the largest pores collapse at a given stress increment. Small pores are only compressed when all the macropores have been completely destroyed by the loading. These results were confirmed by other existing data $[10,11,12]$. Soil fabric is also sensitive to suction increase as evidenced by other authors $[13,14]$ who investigated the fabric of a compacted glacial till under different suctions, from saturation up to $2500 \mathrm{kPa}$. They have shown that suction increase provoked a progressive rise in the microporosity associated with macroporosity reduction. Only a few authors $[15,16]$, have, however, studied fabric modification during the mechanical loading of an 
unsaturated soil. These authors used remoulded Boom clay, which is a swelling material, and a synthetic model clay named Na-Laponite, and they have shown that suction affected the deformation process. Their interest was essentially focused at the clay particle level and the initial fabric of these materials was very different from the "double structure" encountered in natural or compacted soils, as the materials they used were initially remoulded. Hence, it is difficult to extrapolate their conclusions to natural or compacted soils with a "double structure" and the understanding of fabric modification during hydromechanical loading is limited.

In addition to the emphasis on determining soil fabric modification during loading, the hydromechanical behaviour of compacted soils has been extensively studied over the last thirty years. Many results are available in the field of experimental characterisation of unsaturated soils $[8,17,18]$ as well as in the field of constitutive modelling $[19,20$, 21]. An interesting point, shown by a few studies, is the importance of initial sample fabric on the relationship between suction and the slope of the plastic compression line $\lambda(\mathrm{s})[22,23]$. Understanding of the relationship between fabric and compressibility is, however, limited and requires more studies combining fabric determination and a hydromechanical approach for this to be better understood and defined.

Considering this state of the art, a project was undertaken to characterise the modification of soil fabric during mechanical loading and to improve the understanding of the hydromechanical behaviour of a compacted soil. The suction controlled oedometer that was used is presented first. The mercury intrusion porosimetry technique was selected for the determination of the fabric of the soil sample and its basic principle is also explained in the first part of the paper. The influence of suction and of 
mechanical stress are then discussed. The final section outlines the main conclusions that can be inferred from these results.

\section{EXPERIMENTAL DEVICES AND TECHNIQUES}

\section{Mechanical devices}

Two kinds of devices were used to perform the mechanical tests: standard oedometers and a suction controlled oedometer, especially developed for this study, which employs the air overpressure method for suction control (Fig. 1). The basic principle of this method was presented by Richards (1935) [24]. An air pressure/volume controller regulated the air pressure, $\mathrm{u}_{\mathrm{a}}$, inside the sample. The water pressure at the base of the sample, $\mathrm{u}_{\mathrm{w}}$, was maintained constant with a water pressure/volume controller. The imposed matric suction, $s$, was equal to $u_{a}-u_{w}$. The ceramic disc at the base of the sample had an air entry value of $500 \mathrm{kPa}$. The maximum vertical mechanical stress, $\sigma_{\mathrm{v}}$, was $1.5 \mathrm{MPa}$. This was transmitted to the soil sample through the upper chamber of the device, which corresponds to a water tank made with a flexible membrane (Fig. 1). This water was pressurized with a pressure/volume controller. All the controllers used had a precision of $\pm 1 \mathrm{kPa}$ and $\pm 1 \mathrm{~mm}^{3}$. The sample diameter was $6.35 \mathrm{~cm}$ and the initial height about $1.2 \mathrm{~cm}$. This relatively low height was necessary to reduce the time to reach equilibrium after the imposition of a given suction on the soil sample. The vertical load and the suction were increased by steps. Each stress step required a duration of at least $24 \mathrm{~h}$ in order to reach deformation equilibrium. The duration of a suction step was typically between 2 and 3 days. The water exchange generated by the imposition of a given suction step was considered stabilized when the exchanged water volume was 
lower than $10 \mathrm{~mm}^{3}$ for 12 hours. In the case of the standard oedometer, the sample height was about $1.5 \mathrm{~cm}$ and the diameter was $6 \mathrm{~cm}$.

All the results will be given with respect to the net stress $\sigma^{*}=\sigma-\mathrm{u}_{\mathrm{a}}$ and the suction $\mathrm{s}=$ $\mathrm{u}_{\mathrm{a}}-\mathrm{u}_{\mathrm{w}}$ in the following sections. These two independent variables were defined from the total stress $\sigma$, the pore air pressure $u_{a}$, and the pore water pressure $u_{w}[25,26,27]$.

\section{Soil fabric determination with mercury intrusion porosimetry (MIP)}

There are several ways to determine soil fabric: scanning electron microscopy [28], optical microscope [23], nitrogen adsorption [29], mercury intrusion porosimetry (MIP) [6], etc. For this study, this last technique was selected because it allows the measurement of a wide pore-size range, from a few nanometres up to several tens of micrometers, and it permits the identification of the different soil pore classes.

The theoretical bases for the determination of soil fabric with MIP are very similar to those of the pressure plate test. In the case of MIP, the non-wetting fluid is mercury and air is the wetting fluid. The mercury pressure is increased by steps and the intruded volume of mercury is monitored for each pressure increment. Assuming that soil pores are cylindrical flow channels, Jurin's equation is used to determine the pore radius associated with each mercury pressure increment:

$$
\mathrm{r}=\frac{2 \mathrm{~T}_{\mathrm{s}} \cos \alpha}{\mathrm{P}}
$$

where $\mathrm{r}$ corresponds to the entrance pore radius, $\mathrm{T}_{\mathrm{s}}$ to the surface tension of the liquid $\left(0.485 \mathrm{~N} . \mathrm{m}^{-1}\right.$ for mercury and $0.07275 \mathrm{~N} . \mathrm{m}^{-1}$ for water $), \alpha$ to the contact angle of fluid interface to solid $\left(0^{\circ}\right.$ for air-water and $140^{\circ}$ is an average value for mercury-air interface as suggested in [30]), and $\mathrm{P}$ to the pressure difference between the two interfaces $(\mathrm{Pa})$. An MIP test gives the cumulative mercury volume intruded as a function of the 
equivalent pore radius. To further interpret MIP data, some authors have proposed the determination of the pore-size distribution (PSD) of the sample [31], defined as follows:

$f\left(\log r_{i}\right)=\frac{\Delta V_{i}}{\Delta(\log r)}$

where $\Delta \mathrm{Vi}$ is the injected mercury volume at a given pressure increment corresponding to pores having a radius of $r_{i} \pm\left(\Delta \log r_{i}\right) / 2$. It is necessary to use a logarithmic scale because a wide range of pore radii, i.e. several orders of magnitude, is investigated. The PSD curves that are presented in this paper were all determined using a constant value of $\Delta(\log r)$ equal to 0.3 . It should be pointed out that the determination of PSD with MIP is influenced by several experimental side effects, such as pore entrapment, pore neck, etc. As a consequence, the measured PSD might differ from the real PSD of the tested soil and the pore radius associated with each pressure increment is only an entrance pore radius. As a simplification, the term "entrance" will be omitted in the following when dealing with pore radius calculated from MIP data. More details about these phenomena are available in [9].

After an experiment, each soil sample was carefully cut in small pieces of approximately $1 \mathrm{~g}$, and those were used to conduct the MIP test. Due to technical requirements, the MIP test must be conducted on totally dried soil pieces. Among the available dehydrating methods, oven drying and air-drying should be avoided since they induce strong soil pore geometry modification. The freeze-drying method is the least disturbing preparation technique for water removal [32]. Hence, it was selected for our study, although it gives less reproductive results than oven drying [30]. Soil pieces were quickly frozen with liquid nitrogen (temperature of $-196^{\circ} \mathrm{C}$ ) and then placed in a commercially available freeze-drier for approximately 1 day for the sublimation of the 
water. The samples were subsequently kept inside desiccators until the MIP tests were performed with a Porosimeter 2000 (Carlo Erba Instruments).

\section{TESTED MATERIAL}

The tested soil was a sandy loam from the eastern part of Switzerland (morainic soil of the Swiss Central Plateau). The plasticity index of the soil was about $12 \%$ and its liquid limit close to $30 \%$. The weight of the soil particles was equal to $26.1 \mathrm{kN} \cdot \mathrm{m}^{-3}$. In this study, all the samples were prepared using the same procedure. After sampling in the field, the soil was air-dried and gently crushed after several days. Aggregates between 0.4 and $2 \mathrm{~mm}$ were selected by sieving and were then wetted up to a gravimetric water content of about $14 \%$ and stored in an airtight container for at least one week in order to reach moisture equilibrium. The aggregates were then statically compacted directly inside the desired oedometer up to a target dry density of $14 \mathrm{kN} \cdot \mathrm{m}^{-3}$. This pore class was selected in order to avoid pore filling by the finer particles. In a last stage, the samples were saturated by imposing a low water head, of a few centimetres, at the base. After this saturation phase, the mass water content of the samples was between 36 and $37 \%$. In the case of tests conducted under suctions higher than 0 , the desired suction was applied in several steps prior to the application of the mechanical loading.

\section{EXPERIMENTAL PROGRAM}

The experimental program was set up for the determination of both the hydromechanical behaviour of the material and the fabric modifications induced by the stress path followed. The initial state of the samples, after the saturation phase, corresponds to point A in Fig. 2. This state of the material will be considered as the 
reference state in the following sections. Three test series were performed (Fig. 2 and Tab. 1):

- Tests D1 to D4: sample suction was increased by steps up to a given suction $(50,100$, 200 or $400 \mathrm{kPa}$ ) in a pressure plate device. Their fabric was then determined by MIP. This series was carried out for the determination of the soil water characteristic curve and for the evaluation of drying influence on soil fabric.

- Tests Sat1 to Sat3: three samples were mechanically loaded up to a given vertical stress $(60,250$ or $1000 \mathrm{kPa})$. A standard oedometer was used to perform this test series. After unloading back to $10 \mathrm{kPa}$, the sample fabric was evaluated by MIP. This series was carried out for the characterisation of soil fabric modification provoked by mechanical loading under a saturated state.

- Tests Unsat1 and Unsat2: the samples were first dried inside the suction-controlled oedometer up to 100 and $200 \mathrm{kPa}$, respectively. Second, each sample was loaded to a vertical net stress of $1000 \mathrm{kPa}$ under constant suction and then unloaded to $10 \mathrm{kPa}$. These tests were performed for the evaluation of suction influence on mechanical behaviour and on the deformation process of the tested soil.

It should be pointed out that the MIP tests were performed after the mechanical unloading in the case of tests Sat1 to Sat3, Unsat1 and Unsat2. Consequently, for these samples, the obtained PSD can only be used to evaluate the influence of plastic phenomena on soil fabric.

\section{FABRIC MODIFICATIONS INDUCED BY SUCTION INCREASE}

In this section, the results obtained for the characterisation of suction influence on soil fabric are presented. First, the procedure used for the determination of samples PSD is 
discussed. Second, the soil-water characteristic curve of the tested samples is given and then, the fabric modifications due to suction increase are addressed.

\section{Check of the PSD determination procedure}

An important question when using MIP for the determination of soil PSD is to establish whether or not the sample fabric was modified significantly during its dehydration by freeze-drying. In this context, two aspects were studied: repeatability and the influence of the freeze-drying technique on the obtained PSD.

To check repeatability, two soil pieces were taken from sample Sat3 after the mechanical test and further analysed by MIP. These results are given in Figure 3 and no significant differences could be seen between these curves. Consequently, these results indicate satisfactory repeatability. The dehydration technique influence was then tested. Two MIP tests were performed on two soil pieces taken on the same soil sample (D2). In one case, freeze-drying was used to perform the dehydration and, in the other case, oven drying was employed. The results of the two MIP tests are plotted in Figure 4 and it can be seen that the drying technique significantly affected the PSD. To further interpret these data, the porosity of each sample was determined by assuming that the injected mercury volume corresponds to the total pore volume of a sample. The porosity of the oven-dried sample estimated by MIP data was about $33.9 \%$; those of the freezedried sample was about $39.9 \%$. Knowing the dimensions of sample D2, its weight and its water content, it was possible to determine its porosity. The value of its porosity was 42.1\%. Consequently, oven drying induced a significant porosity reduction compared to that obtained by freeze-drying. This result is similar to other data from the literature, e.g. [33]. Two reasons could explain the differences between the measured porosity and the porosity estimated from MIP data in the case of the freeze-dried sample. First, with 
the porosimeter device used, it was not possible to evaluate the volume of macropores with a radius greater than $70 \mu \mathrm{m}$, because a minimal pressure was required to fill the sample holder with mercury initially. Second, the volume of micropores with a radius less than $0.05 \mu \mathrm{m}$ was not measured precisely. Below that pore radius value, which roughly corresponds to a mercury injection pressure of about $15 \mathrm{MPa}$, some troubles were encountered with the porosimeter device. This affected the MIP results and thus, the PSD calculated with Equation 1. This phenomenon was noticed in most of the tests. However, the difference between the MIP estimated porosity and the measured porosity was typically lower than $5 \%$, and this is the same order of magnitude as found in data reported by other authors [34]. Another interesting point is that with the freeze-drying technique, the porosity of the sample was not overestimated. Other authors reported that the formation of large ice crystals inside the soil sample provokes a significant porosity increase if the cooling phase of the freeze-drying procedure is not efficient [35].

Considering the good repeatability and the satisfactory porosity estimations made, it was possible to conclude that the freeze-drying procedure was performed in an appropriate manner.

\section{Soil-water characteristic curve}

For the determination soil-water characteristic curve of the tested material, data from tests D1 to D4 were used. All these data are plotted together in Figure 5. The air entry value of the tested material was between 5 and $20 \mathrm{kPa}$. This low value could be explained by the initial density of the samples which permitted the existence of large macropores that are emptied at relatively low suctions during suction increase. Using Jurin's equation (Eq. 1) it was possible to calculate the pore radius that corresponds to the air entry value, which is approximately between 1 and $30 \mu \mathrm{m}$. 


\section{Suction increase effect on PSD}

Sample I fabric was determined in order to characterise the sample's initial fabric under null suction (Fig. 6). The PSD of sample I had a shape very similar to the PSD of a silt compacted dry of optimum [36], as two pore classes can be seen (micro and macropores). This test confirms the ability of the chosen procedure to prepare samples with a "double structure" initially. The limit between the two pore classes is about $1 \mu \mathrm{m}$. Considering that limit, the micro and the macroporosity components of the soil sample porosity were evaluated. These data are given in Table 2.

Knowing the sample's initial fabric, the study of the influence of drying on fabric under null vertical stress was carried out. It may be seen in Figure 7 that the suction increase induced strong modifications of the soil fabric. First, suction increase from 0 to $50 \mathrm{kPa}$ produced a strong reduction in the total soil porosity (Tab. 2) and this porosity reduction occurred through an important modification of the macroporosity (Fig. 7). It is interesting to note that the reduction of the amount of macropores is accompanied by a relative increase in the microporosity which can be explained by the shrinkage of the macropores. The imposition of suctions higher than $50 \mathrm{kPa}$ did not lead to an important total porosity reduction (Tab. 2). This indicates that the shrinkage limit of the samples has been reached. Hence the shrinkage limit is equal to a mass water content of about $22 \%$, which corresponds to a suction of $50 \mathrm{kPa}$ (Fig. 5). Despite the shrinkage limit reached at $\mathrm{s}=50 \mathrm{kPa}$, the fabric still experienced significant modifications until the application of $\mathrm{s}=200 \mathrm{kPa}$, as seen in Figure 7. Between 50 and $200 \mathrm{kPa}$, pores with a radius of between 2 and $7 \mu \mathrm{m}$ were subjected to important shrinkage, resulting in an increase in the microporosity. It is interesting to note that macropores with a radius greater than $7 \mu \mathrm{m}$ were not affected by the application of suction higher than $50 \mathrm{kPa}$. 
From $\mathrm{s}=200 \mathrm{kPa}$ to $400 \mathrm{kPa}$, no significant fabric modification was observed. The comparison of all of these PSDs shows that the drying process did not affect pores smaller than $0.1 \mu \mathrm{m}$. As a conclusion, it could be stated that drying produces a reduction in the soil total porosity which corresponds mainly to a reduction in the macropore volume. Associated with this phenomenon, an increase in the micropore volume was also observed and some macropores were not affected by the drying process. It is also interesting to note that, despite the fact that the total porosity of the samples was roughly constant above a suction of $50 \mathrm{kPa}$, strong modifications of the fabric were obtained above that suction value. Hence, fabric changes can occur without important variation in total porosity, i.e. at constant void ratio. These results are partially in accordance with the data presented by other authors who observed that suction increase leads to total destruction of the macroporosity $[13,14]$.

Several explanations could be presented to explain the fact that a certain class of macropores was not affected by shrinkage during suction increase. First, fracturing of the MIP samples during the freeze-drying process could have generated these macropores. To study that hypothesis, MIP data were used to calculate the amount of water exchanged during the determination of the soil-water characteristic curve of the material (Tab. 3). There was satisfactory agreement between the two kinds of data for the different suction steps. The most important difference was obtained during the first suction increase step (from 0 to $50 \mathrm{kPa}$ ). This may be related to the MIP technique because larger pores cannot be measured with a porosimeter. This demonstrates that the macropores were not generated during the freeze-drying process. A second explanation takes into account the fact that pore shrinkage is due to water menisci that progress from larger pores towards finer pores as suction is increased. During a given suction step, 
only a certain pore class was submitted to water tension, and hence to shrinkage. In the first suction step, from 0 to $50 \mathrm{kPa}$, shrinkage concerned only pores with a radius greater than $2.92 \mu \mathrm{m}$. Above a suction of $50 \mathrm{kPa}$, the remaining pores (radius greater than $2.92 \mu \mathrm{m}$ ) were no longer submitted to water tension, and hence they were not significantly affected by shrinkage during subsequent loading steps. The procedure used for the preparation of the samples should also be taken into account. All the samples are made from the compaction of aggregates. The spaces between these aggregates certainly correspond to the macropore class seen on sample I (Fig. 6). During drying, the macropores were progressively emptied but the strength of the aggregates limited the shrinkage of the macropores, explaining the observed phenomena. These observations demonstrate the importance of the initial fabric of the samples on their hydraulic behaviour.

\section{MECHANICAL BEHAVIOUR AND FABRIC MODIFICATION DURING}

\section{LOADING}

The second aspect studied in this project was the influence of mechanical loading on fabric. Two cases will be discussed in the following sections: loading under a saturated state and loading under an unsaturated state.

\section{Saturated mechanical behaviour and fabric}

Three samples were loaded up to a different vertical stress in several steps and their PSDs were then determined. The stress paths followed are described in Figure 2 and the corresponding compression curves are plotted in Figure 8. The different characteristics of the tested samples are given in Table 4. In this table, $\mathrm{w}_{\mathrm{f}}$ is the final gravimetric water content, $\kappa=\Delta$ (e) $/ \Delta \ln \left(\sigma^{*}\right)$ the slope of the rebound compression line, $\lambda(\mathrm{s})=\Delta(\mathrm{e}) /$ 
$\Delta \ln \left(\sigma^{*}\right)$ the slope of the plastic compression line and $p_{0}(s)$ is the apparent precompression stress. Good repeatability was observed among all the saturated oedometric tests. The precompression stress was approximately the same in all tests, equal to $20 \mathrm{kPa}$.

The results of the MIP tests conducted on samples Sat1 to Sat3 after the oedometric tests are plotted in Figure 9 and the results obtained with sample I are also presented. This figure shows the modification of sample fabric as a function of the maximum vertical stress experienced by the soil. Deformation occurred in a very progressive way: the higher the applied stress, the lower the final porosity (see Tab. 2). An interesting point is that void ratio reduction occurred by a progressive diminution of the amount of macropores without significant modification of the microporosity up to a vertical stress of $250 \mathrm{kPa}$ (test Sat2). Beyond this stress value, an increase in the microporosity can be seen from the PSD curves. Consequently, it is possible to state that deformation is due mainly to macroporosity reduction and that during saturated mechanical loading, fabric depends on the maximum vertical stress experienced by the material.

\section{Unsaturated mechanical behaviour and fabric}

Two unsaturated oedometric tests were conducted: Unsat1 and Unsat, where the applied suction during the mechanical loading was 100 and $200 \mathrm{kPa}$, respectively. The results of these tests are plotted in Figure 10 and the result of test Sat3 (saturated sample loaded to $1000 \mathrm{kPa}$ ) is also given. The different characteristics of these samples, as well as the mechanical parameters, are presented in Table 4. It is interesting to note that only slight differences were observed between the compression curves of tests Unsat1 and Unsat2. Hence, the major modification of the hydromechanical behaviour of the tested samples 
due to suction change occurred between 0 and $100 \mathrm{kPa}$. This kind of behaviour is similar to the mechanical behaviour of this kind of soil, e.g. [19].

It could be seen that the stress $p_{0}(\mathrm{~s})$ is significantly higher in tests Unsat1 and Unsat2 than in test Sat3. This result is in agreement with the majority of data in the literature which show an increase in pressure $p_{0}(s)$ with suction $[19,37,38]$. The value of $\kappa$ tends to increase with suction; that result is also similar to existing data $[19,37,38]$. It is interesting to note that the slope $\lambda(\mathrm{s})$ tends to decrease with the increase in suction. Only a few authors have observed such behaviour on compacted soils. Sivakumar and Wheeler (2000) [22] have shown that, in the case of a sample compacted under a vertical stress of $400 \mathrm{kPa}, \lambda(\mathrm{s})$ increased with suction, whereas in the case of a sample compacted under a vertical stress of $800 \mathrm{kPa}, \lambda(\mathrm{s})$ decreased continuously with suction. This mechanical behaviour is certainly related to the relatively loose initial density of the samples. That conclusion is supported by other data obtained on a compacted swelling soil which have shown the importance of sample preparation technique on unsaturated mechanical behaviour [23].

Another interesting point is that the compression curves of samples Unsat1 and Unsat2 tend to join the curve of sample Sat3 above an applied vertical stress of about $800 \mathrm{kPa}$ (Fig. 10). This indicates that the influence of suction on the hydromechanical behaviour of the tested samples diminished progressively as the applied stress increased. An author has observed this kind of behaviour on a silty soil and a possible explanation takes into account the modification of the degree of saturation of the tested sample during each test [39]. It should be noted that in an unsaturated soil, the effect of suction on the mechanical behaviour has to be related to meniscus water that acts between soil particles, especially in the case of silty or sandy soils. The existence of the meniscus is 
due to the coexistence inside the soil sample of water, solid and air phases, the role of the meniscus on mechanical behaviour is therefore related to the degree of saturation. The variation of the degree of saturation of sample Unsat1 and Unsat2, calculated for each suction/stress step from the amount of exchanged water, is plotted in Figure 11. It can be seen that both samples were unsaturated at the beginning of the loading phase. However, due to void ratio reduction during the mechanical loading, their degree of saturation was close to complete saturation at the end of the loading phase. Under this condition, the amount of meniscus water between soil particles decreased during the mechanical loading. That can explain the fact that the influence of suction on the hydromechanical behaviour diminished as the mechanical loading progressed. Another interesting point is that the mechanical unloading is associated with a decrease in the degree of saturation in both tests. These results demonstrate that the degree of saturation should be taken into account together with the applied suction to interpret the results of unsaturated mechanical tests. These observations can be further interpreted considering the fabric of the samples.

The fabric of the tested samples was also determined to investigate the influence of suction on the deformation process. However, due to a technical breakdown during the MIP test conducted with sample Unsat1, only the MIP data for sample Unsat2 are available. The results are plotted in Figure 12 where the results of tests I and D3 are also reported (test I represents the initial state and the fabric of sample D3 corresponds to sample Unsat2 fabric prior to the mechanical loading). Porosity estimation data are indicated in Table 2. As seen in Figure 12, the mechanical loading is associated with a decrease in the mean micropore radius in the case of test Unsat2 as well as a significant reduction in macroporosity. To further interpret these data, the link between fabric and 
the mechanical behaviour was then studied. As mentioned before, the mechanical unloading is associated with an important decrease in the degree of saturation in test Unsat2 (Fig. 11). From Eq. 1, a suction of $200 \mathrm{kPa}$ corresponds to a pore radius of about $0.73 \mu \mathrm{m}$, and during a mechanical test, only pores having a radius smaller than this value were saturated. The degree of saturation is, consequently, directly related to the amount of macropores whose radius was greater than $1 \mu \mathrm{m}$ initially (Fig. 6). Hence, the desaturation of sample Unsat2 during unloading can be explained only if the macropores presented in Figure 12 were generated during the unloading phase, as sample Unsat2 was nearly saturated at the end of the mechanical loading. Consequently, it can be stated that, at the end of the loading phase, almost all larger pores had collapsed due to the mechanical loading. Thus, this indicates that the macropores seen in Figure 12 must certainly have been generated during the unloading phase. Hence, the impact of the mechanical loading on the soil fabric of sample Unsat2 was limited by the applied suction. The deformation process under an unsaturated state is therefore totally different from what was seen during the tests performed under null suction (tests Sat1 to Sat3), where the fabric after mechanical loading was dependent on the maximum vertical stress experienced by the soil.

\section{CONCLUSION}

The paper presents the results of a study undertaken to characterise the hydromechanical behaviour and the evolution of fabric as a function of the imposed stress/suction path of a compacted soil. The link between fabric and mechanical behaviour was also examined. A suction-controlled oedometer was used to characterise the hydromechanical behaviour of the material and mercury intrusion porosimetry was 
employed for the determination of sample fabric after different types of hydromechanical loading. All of the tested samples had a fabric with micro and macropores initially.

First, the influence of suction increase on the fabric of compacted silt was investigated. It appeared that fabric is extremely sensitive to suction modification and it was also observed that important fabric change could occur without significant shrinkage of the material. This means that soil fabric modification could take place at constant void ratio. Another interesting point was that a certain macropore class was not affected by drying. This seems to be related to the initial fabric of the samples that were made by the compaction of aggregates.

The results obtained confirmed the deformation process seen by other authors for mechanical loading under a saturated state. As the applied mechanical stress increased, deformation progressed from larger pores towards finer ones. The role of suction on the deformation process during mechanical loading was subsequently investigated. It appears that knowing the degree of saturation during mechanical loading is useful to interpret the results of unsaturated mechanical loading tests. It was shown that the suction influence on the hydromechanical behaviour tends to diminish with loading, as the unsaturated compression curves tend to join the saturated compression curve at the end of the mechanical loading. This phenomenon was related to an increase in the degree of saturation which is close to $100 \%$ at the end of the mechanical loading. The MIP tests have also shown that the hydromechanical behaviour of compacted soil is directly related to its fabric. 


\section{ACKNOWLEDGMENTS}

This research was funded by the Swiss Agency for Environment, Forests and Landscape (OFEFP) through the contract $\mathrm{n}^{\circ} 2001 . \mathrm{H} .10$ granted to the second author. The authors thank Dr P. Weisskopf (FAL) and Dr Th. Anken (FAT) for providing the soil used in the study. They are also grateful of the Powder Technology Laboratory (EPFL) assistance to perform the freeze-dryings tests. 


\section{REFERENCES}

[1] Lambe TW. The engineering behaviour of compacted clays. Journal of the Soil Mechanics and Foundation Division ASCE 1958; 84: 1-35.

[2] Tamari S. Relations between pore-space and hydraulic properties in compacted beds of silty-loam aggregates. Soil Technology 1984; 7: 57-73.

[3] Brustaert W. The permeability of a porous medium determined from certain probability laws for pore-size distribution. Water Resources Research 1968; 4: $425-434$.

[4] Burland JB. Thirtieth Rankine lecture: on the compressibility and shear strength of natural clays. Géotechnique 1990; 40: 327-378.

[5] Barden L, Sides GR. Engineering behavior and structure of compacted clays. Journal of Soil Mechanics and Foundation Analysis 1970; 96: 1171-1200.

[6] Sridharan A, Altaschaeffl AG, Diamon S. Pore-size distribution studies. Journal of the Soil Mechanics and Foundation Division ASCE 1971; 97: 771-787.

[7] Collins K, McGown A. The form and function of microfabric features in a variety of natural soils. Géotechnique 1974; 24: 223-254.

[8] Alonso EE, Gens A, Hight DW. Special problem soils. General report. In Proceedings of the $9^{\text {th }}$ European Conf. on Soil Mechanics and Foundation Engineering, Dublin, Ireland, 1987; 5.1-5.60.

[9] Delage P, Lefebvre G. Study of the structure of a sensitive Champlain clay and of its evolution during consolidation. Canadian Geotechnical Journal 1984; 21: 2135.

[10] Griffiths FJ, Joshi RC. Change in pore-size distribution due to consolidation of clays. Géotechnique 1989; 39: 159-167. 
[11] Coulon E, Bruand A. Effects of compaction on the pore space geometry in sandy soils. Soil \& Tillage Research 1989; 15: 137-152.

[12] Lapierre C, Leroueil S, Locat J. Mercury Intrusion and Permeability of Louisville clay, Canadian Geotechnical Journal 1990; 27: 761-773.

[13] Simms PH, Yanful EK. Measurement and estimation of pore shrinkage and pore distribution in a clayey till during soil-water characteristic curve tests. Canadian Geotechnical Journal 2001; 38: 741-754.

[14] Simms PH, Yanful EK. Predicting soil-water characteristic curves of compacted plastic soils from measured pore-size distribution. Géotechnique 2002; 52: 269278.

[15] Al-Mukhtar M, Belanteur N, Tessier D, Vanapalli SK. The fabric of a clay soil under controlled mechanical and hydraulic stress states. Applied Clay Science 1996; 11: 99-115.

[16] Qi Y, Al-Mukhtar M, Alcover JF, Bergaya F. Coupling analysis of macroscopic and microscopic behaviour in highly consolidated Na-laponite clays. Applied Clay Science 1996; 11: 185-197.

[17] Lloret A, Villar MV, Sanchez M, Gens A, Pintado X, Alonso EE. Mechanical behaviour of heavily compacted bentonite under high suction changes. Géotechnique 2003; 53: 27-40.

[18] Cuisinier O, Masrouri F. Comportement hydromécanique d'un sol gonflant sous très fortes succions. Comptes Rendus Mécanique 2003; 333: 203-210.

[19] Alonso EE, Gens A, Josa A. A constitutive model for partially saturated soils. Géotechnique 1990; 40: 405-430. 
[20] Gallipoli D, Gens A, Sharma R, Vaunat J. An elasto-plastic model for unsaturated soil incorporating the effects of suction and degree of saturation on mechanical behaviour. Géotechnique 2003; 53 : 123-135.

[21] Laloui L, Klubertanz G, Vulliet L. Solid-liquid-air coupling in multiphase porous media. International Journal of Numerical and Analytical Methods in Geomechanics 2003; 27: 183-206.

[22] Sivakumar V, Wheeler SJ. Influence of compaction procedure on the mechanical behaviour of an unsaturated compacted clay. Part 1: wetting and isotropic compression. Géotechnique 2000; 50: 359-368.

[23] Cuisinier O, Masrouri F. Structure et comportement mécanique d'un sol gonflant non saturé. Revue Française de Géotechnique 2003; 35.

[24] Richards RA. Capillary conduction of liquids through porous medium. Physics 1935; 1: 318-333.

[25] Coleman JD. Stress-strain relations for partly saturated soils. Géotechnique 1962; 12: $348-350$.

[26] Matyas EL, Radhakrishna HS. Volume change characteristics of partially saturated soils. Géotechnique 1968; 18: 432-448.

[27] Fredlund DG, Morgenstern NR. Stress state variables for unsaturated soils. Journal of Geotechnical Engineering 1977; 103: 447-466.

[28] Collins K, McGown A. The form and function of microfabric features in a variety of natural soils. Géotechnique 1974; 24: 223-254.

[29] Guillot X, Al-Mukhtar M, Bergaya F, Fleureau JM. Estimation de la porosité dans un matériau argileux: Porosity assessments in a clay material. Comptes Rendus Geosciences 2002; 334: 105-109 
[30] Penumadu D, Dean J. Compressibility effect in evaluating the pore-size distribution of kaolin clay using mercury intrusion porosimetry. Canadian Geotechnical Journal 2000; 37: 393-405.

[31] Juang CH, Holtz RD. A probabilistic permeability model and the pore-size density function. International Journal of Numerical and Analytical Methods in Geomechanics 1986; 10: 543-553.

[32] Gillott JE. Methods of sample preparation for microstructural analysis of soil. Soil Microscopy $-4^{\text {th }}$ Int. Working-Meeting on Soil Micromorphology, Kingston, Jamaica, 1973; 143-164.

[33] Thompson ML, McBride JF, Horton R. Effects of drying on porosity of soil materials. Soil Science Society of America Journal 1985; 49: 1360-1364.

[34] Romero E, Gens A, Lloret A. Water permeability, water retention and microstructure of unsaturated compacted Boom clay. Engineering Geology 1999; 54: 117-127.

[35] Delage P, Pellerin FM. Influence de la lyophilisation sur la structure d'une argile sensible du Québec. Clay Minerals 1984; 19: 151-160.

[36] Delage P, Audiguier M, Cui YJ, Howatt MD. Microstructure of a compacted silt. Canadian Geotechnical Journal 1996; 33: 150-158.

[37] Laloui L, Geiser F, Vulliet L, Li XL, Bolle A, Charlier R. Characterization of the mechanical behaviour of an unsaturated sandy silt. 14th Int. Conf. on Soil Mechanics and Foundation Engineering, Hamburg, Germany, 1997; Vol.1, 703706.

[38] Rampino C, Mancuso C, Vinale F. Experimental behaviour and modelling of an unsaturated compacted soil. Canadian Geotechnical Journal 2000; 37: 748-763. 
[39] Taibi S. Comportement mécanique et hydraulique des sols soumis à une pression interstitielle négative - Étude expérimentale et modélisation. Doctoral thesis École Centrale Paris, France, 1994; 374 p. 
Table 1. Stress paths followed (see Fig. 2).

\begin{tabular}{llllllllll}
\hline Test & D1 & D2 & D3 & D4 & Sat1 & Sat2 & Sat3 & Unsat1 & Unsat2 \\
\hline Path & A-E & A-F & A-H & A-J & A-B-A & A-C-A & A-D-A & A-F-G-F & A-H-I-H \\
\hline
\end{tabular}


Table 2. Total porosity and macroporosity evaluated from MIP tests results.

\begin{tabular}{ccccc}
\hline Test & $\begin{array}{c}\text { Total pore } \\
\text { volume } \\
\left(\mathrm{mm}^{3} \cdot \mathrm{g}^{-1}\right)\end{array}$ & $\begin{array}{c}\text { Total porosity } \\
(\mathrm{MIP}) \\
(\%)\end{array}$ & $\begin{array}{c}\text { Macropore } \\
\text { volume* } \\
\left(\mathrm{mm}^{3} \cdot \mathrm{g}^{-1}\right)\end{array}$ & $\begin{array}{c}\text { Macroporosity } \\
(\mathrm{MIP}) * \\
(\%)\end{array}$ \\
\hline I & 305.2 & 47.2 & 161.6 & 26.5 \\
D1 & 240.5 & 38.7 & 149.7 & 23.9 \\
D2 & 242.3 & 39.9 & 118.3 & 19.0 \\
D3 & 246.3 & 39.3 & 95.3 & 15.2 \\
D4 & 235.6 & 38.2 & 90.1 & 14.6 \\
Sat1 & 268.3 & 41.3 & 133.3 & 20.5 \\
Sat2 & 232.9 & 37.9 & 95.6 & 15.6 \\
Sat3 & 196.8 & 34.1 & 77.1 & 13.3 \\
Unsat2 & 219.6 & 36.6 & 58.5 & 9.7 \\
\hline
\end{tabular}

*: All macroporosity estimations were made considering a constant limit between micro and macropores equal to $1 \mu \mathrm{m}$. 
Table 3. Determination of the exchanged gravimetric water content during the determination of the soil water characteristic curve.

\begin{tabular}{|c|c|c|}
\hline \multirow{3}{*}{$\begin{array}{l}\text { Suction step }(\mathrm{kPa}) \\
\quad 0 \rightarrow 50\end{array}$} & \multicolumn{2}{|c|}{$\begin{array}{l}\text { Gravimetric water content variation for each suction step } \\
\qquad\left(\mathrm{mm}^{3}\right)\end{array}$} \\
\hline & From MIP data & From retention curve data \\
\hline & 10.8 & 13.5 \\
\hline $50 \rightarrow 100$ & 2.5 & 2.0 \\
\hline $100 \rightarrow 200$ & 1.4 & 0.8 \\
\hline $200 \rightarrow 400$ & 1.9 & 1.6 \\
\hline
\end{tabular}


Table 4. Hydromechanical characteristics of the tested samples.

\begin{tabular}{|c|c|c|c|c|c|c|}
\hline $\begin{array}{c}\text { Test } \\
\text { number }\end{array}$ & $\begin{array}{l}\text { Applied } \\
\text { suction } \\
(\mathrm{kPa})\end{array}$ & $\begin{array}{l}\text { Maximum } \\
\text { applied net } \\
\text { stress } \\
(\mathrm{kPa})\end{array}$ & $(\%)$ & $(-)$ & $\lambda(\mathrm{s})$ & $\mathrm{p}_{0}(\mathrm{~s})$ \\
\hline Sat1 & 0 & 60 & 26.4 & 0.007 & 0.121 & 20 \\
\hline Sat2 & 0 & 250 & 22.4 & 0.007 & 0.117 & 20 \\
\hline Sat3 & 0 & 1000 & 19.1 & 0.008 & 0.113 & 20 \\
\hline Unsat1 & 100 & 1000 & 15.2 & 0.017 & 0.165 & 80 \\
\hline Unsat2 & 200 & 1000 & 14.8 & 0.056 & 0.175 & 95 \\
\hline
\end{tabular}




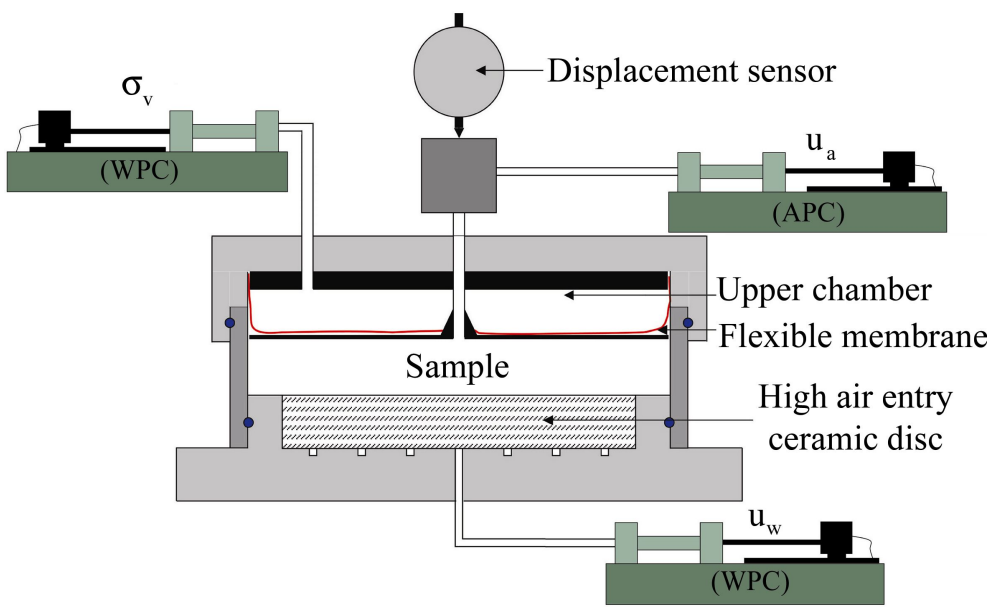

Figure 1. Suction controlled oedometer (APC: air pressure controller; WPC: water pressure controller).

Cuisinier and Laloui. 


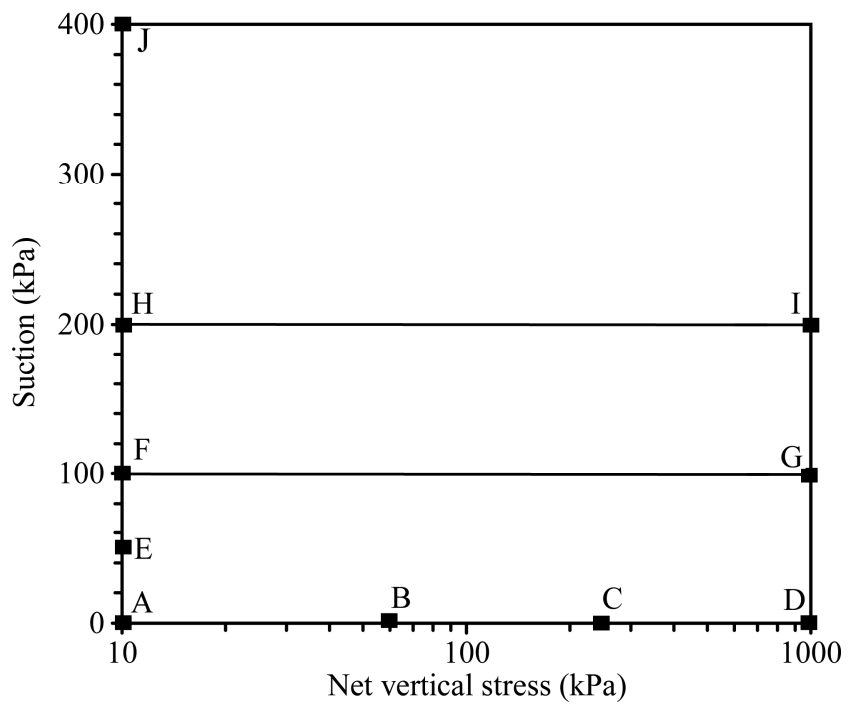

Figure 2. Followed stress paths (see Tab.1 for details).

Cuisinier and Laloui. 

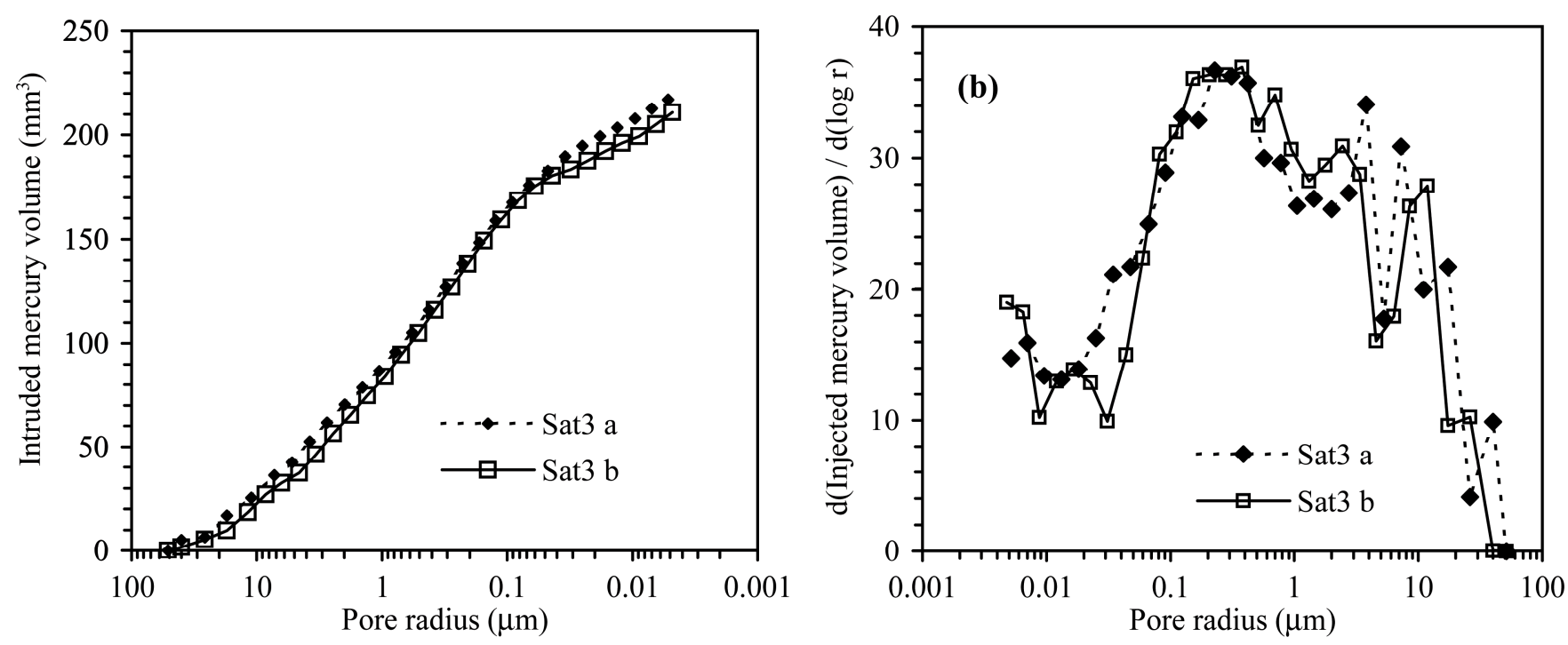

Figure 3. Test of MIP repeatability with sample Sat3: (a) mercury injection curves; (b) PSD.

Cuisinier and Laloui. 

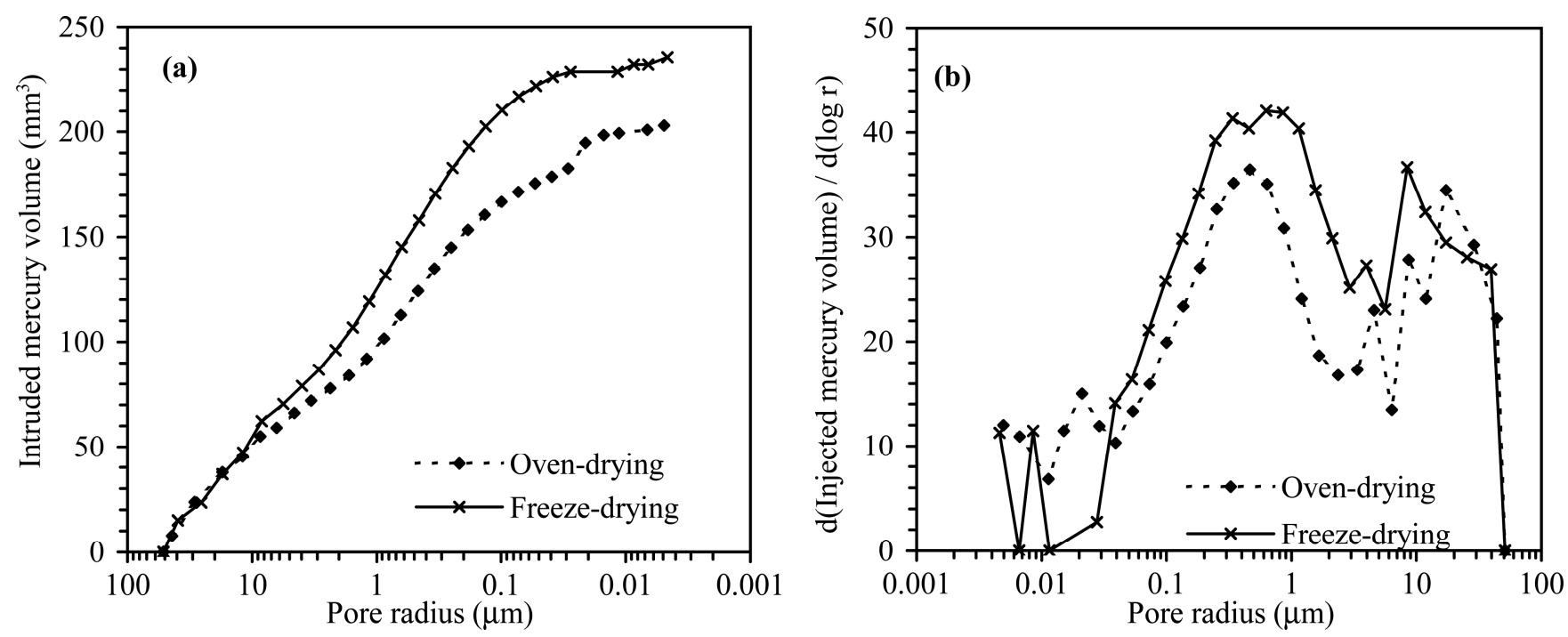

Figure 4. Drying procedure influence on MIP result for sample D2: (a) mercury injection curves; (b) PSD.

Cuisinier and Laloui. 


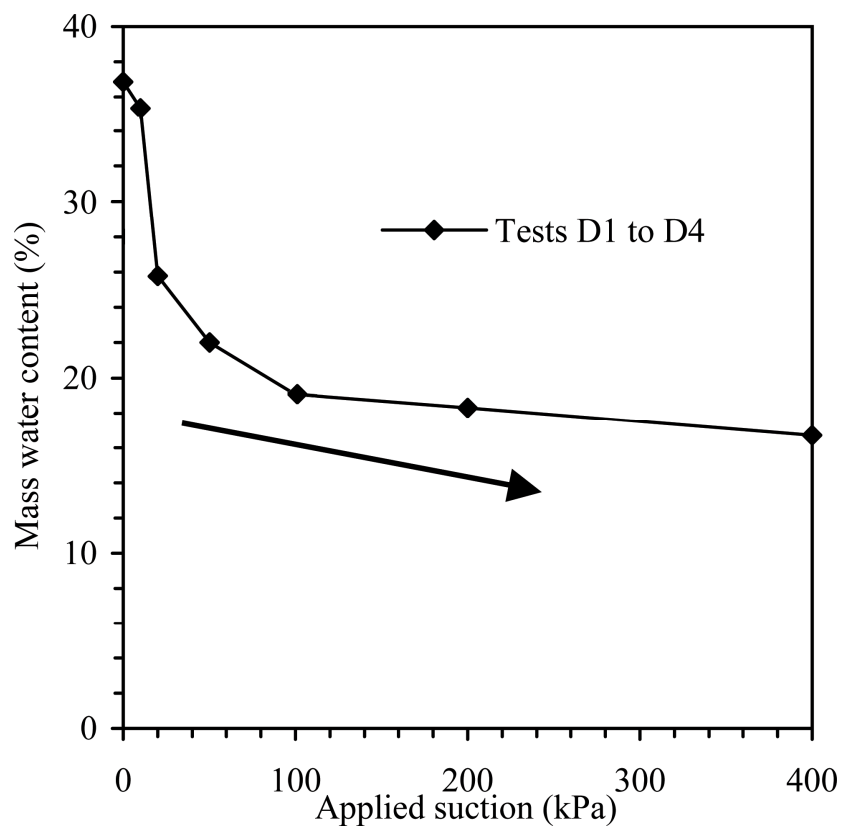

Figure 5. Soil-water characteristic curve of the tested samples.

Cuisinier and Laloui 

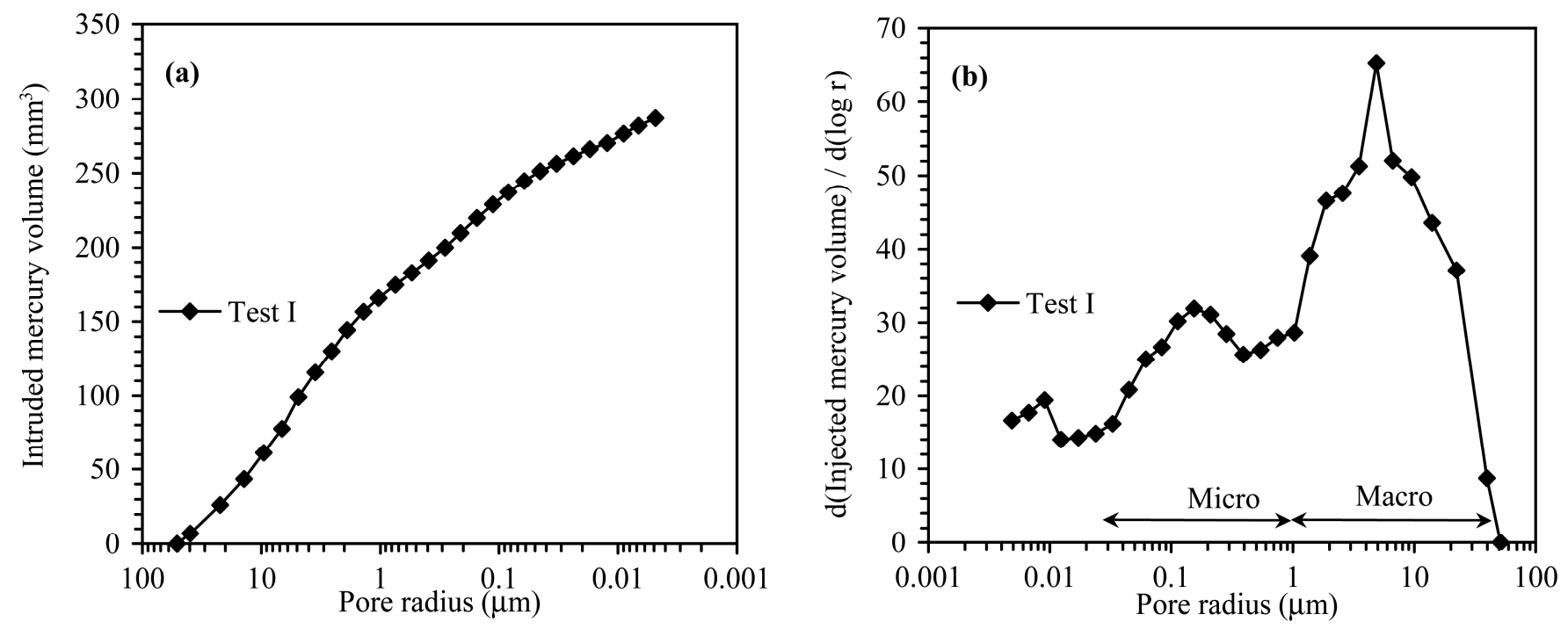

Figure 6. Fabric of sample I (initial state of the samples): (a) mercury injection curves; (b) PSD.

Cuisinier and Laloui. 


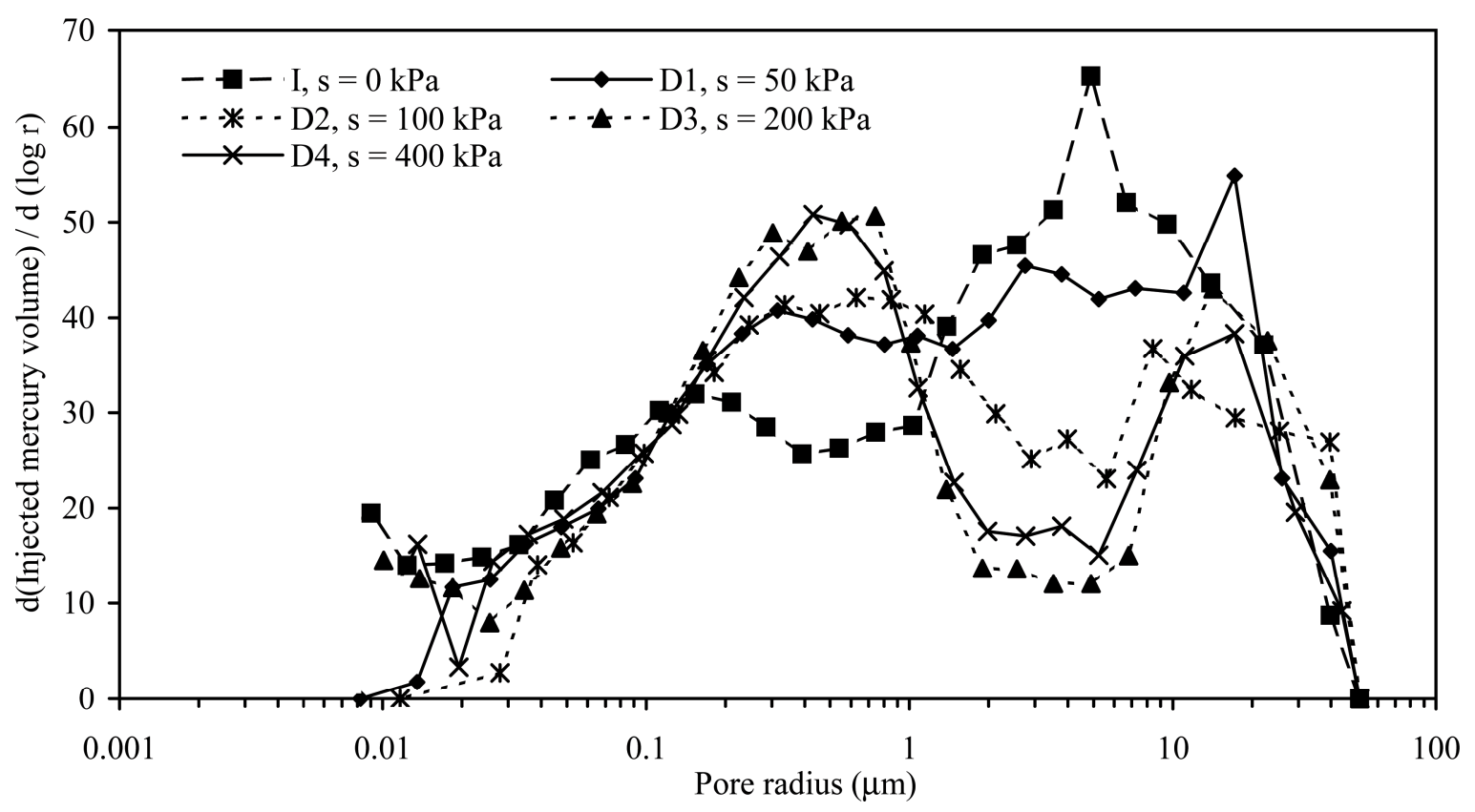

Figure 7. Modification of samples fabric when suction is increased from 0 up to $400 \mathrm{kPa}$ (tests I and D1 to D4).

Cuisinier and Laloui. 


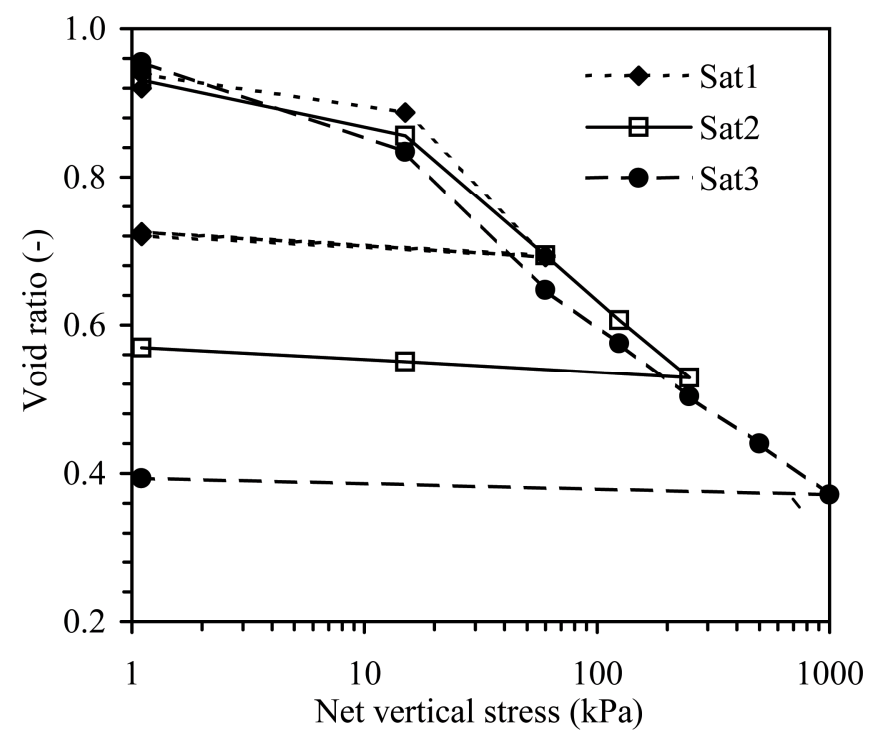

Figure 8. Results of the oedometer tests performed under saturated state (tests Sat1 to Sat3).

Cuisinier and Laloui. 


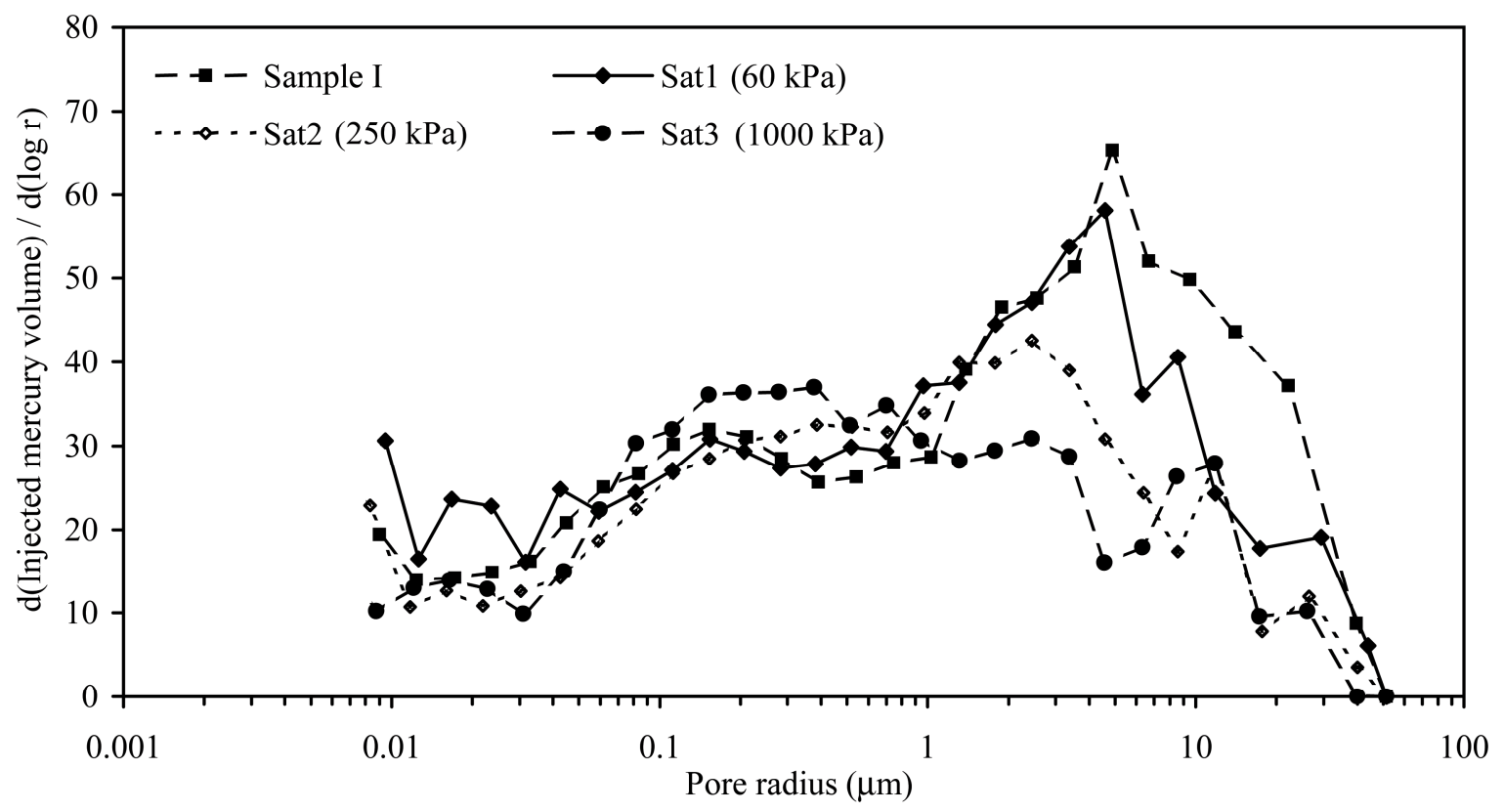

Figure 9. Samples fabric modification during a mechanical loading performed under saturated state (values in brackets indicate the maximum applied net stress).

Cuisinier and Laloui. 


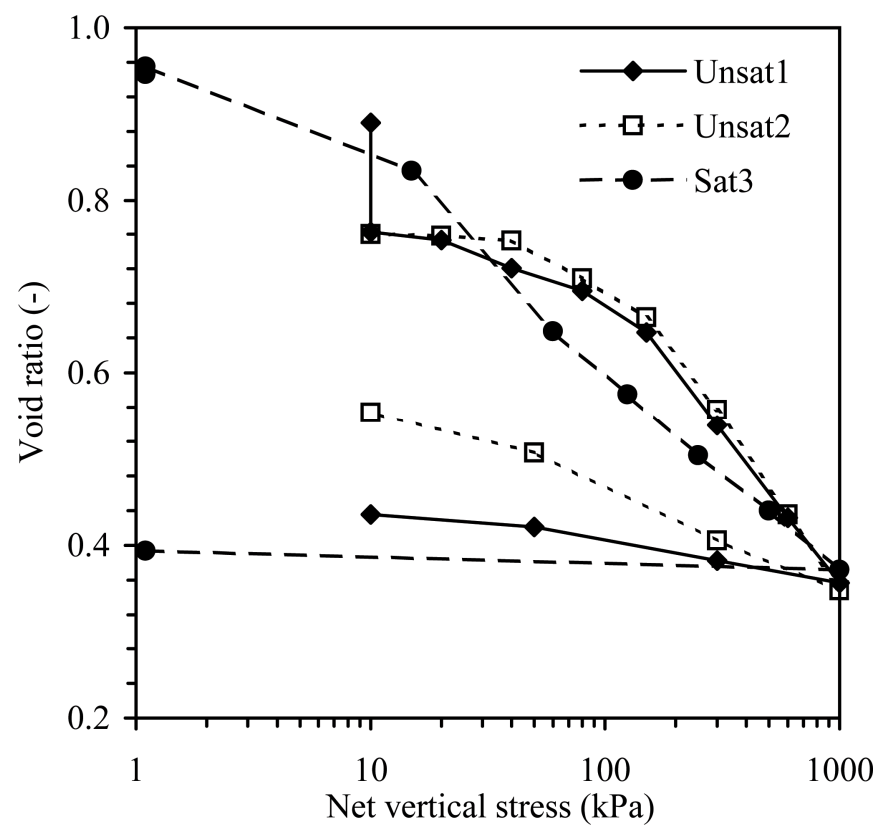

Figure 10. Influence of suction on samples compressibility.

Cuisinier and Laloui. 


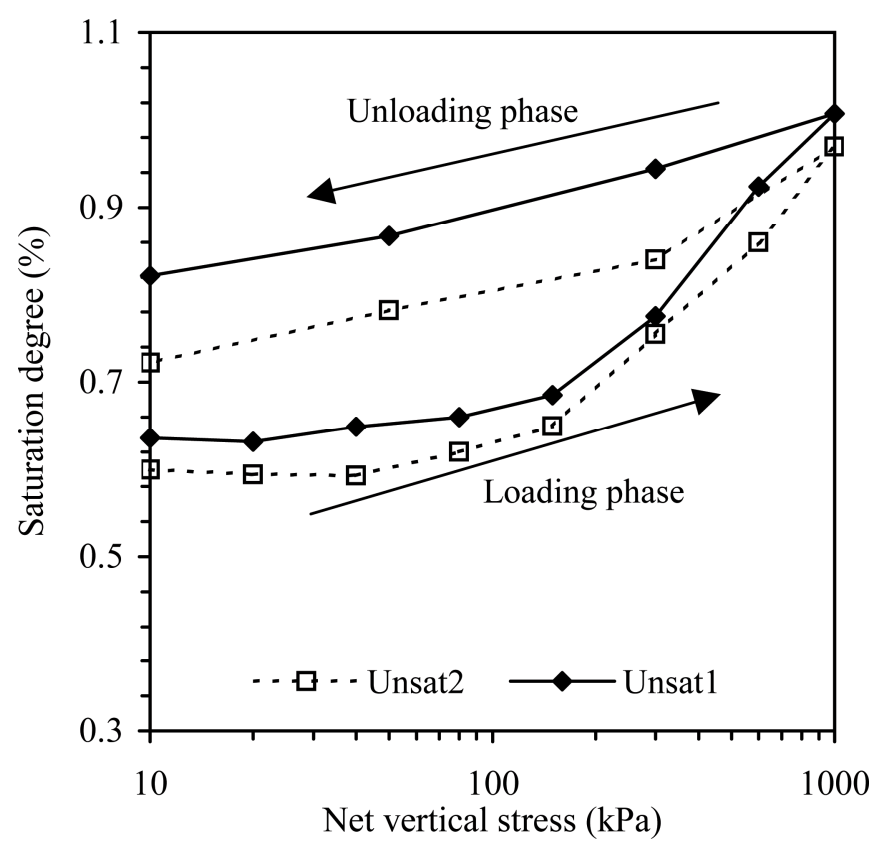

Figure 11. Variation of the saturation degree during loading in tests Unsat1 and Unsat2.

Cuisinier and Laloui. 


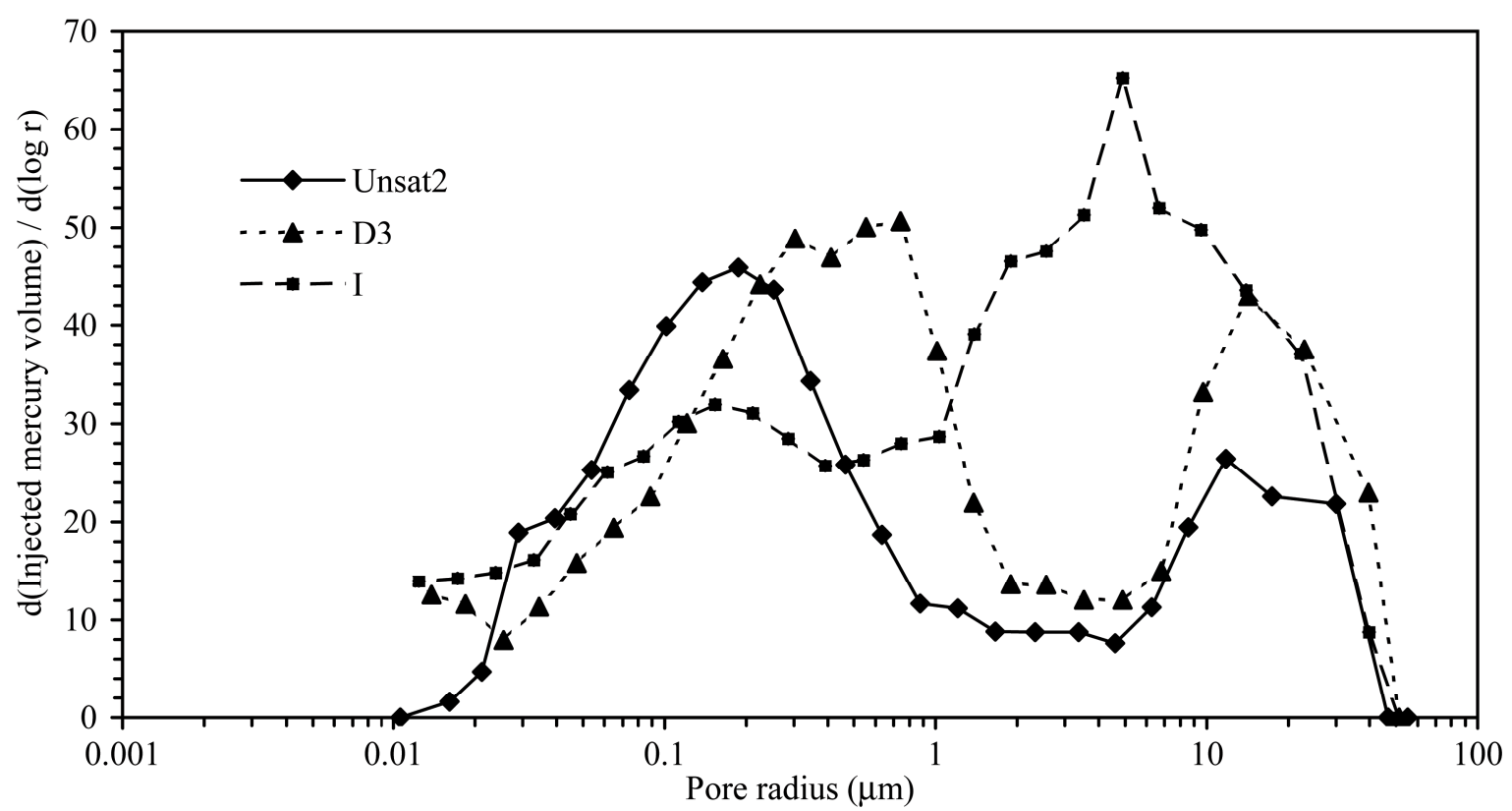

Figure 12. Comparison of tests Unsat2, I and D3 for the evaluation of suction influence on the deformation process.

Cuisinier and Laloui. 